\title{
Familial aggregation of Parkinson's disease and coaggregation with neuropsychiatric diseases: a population-based cohort study
}

This article was published in the following Dove Press journal:

Clinical Epidemiology

\author{
Fu-Chao Liu ${ }^{1,2, *}$ \\ Huan-Tang $\operatorname{Lin}^{1,2, *}$ \\ Chang-Fu Kuo ${ }^{2-4}$ \\ Mei-Yun Hsieh ${ }^{4}$ \\ Lai-Chu See ${ }^{3,5,6}$ \\ Huang-Ping Yu ${ }^{1,2,7}$ \\ 'Department of Anesthesiology, \\ Chang Gung Memorial Hospital, \\ Taoyuan, Taiwan; ${ }^{2}$ College of Medicine, \\ Chang Gung University, Taoyuan, \\ Taiwan; ${ }^{3}$ Division of Rheumatology, \\ Allergy and Immunology, Chang Gung \\ Memorial Hospital, Taoyuan, Taiwan; \\ ${ }^{4}$ Office for Big Data Research, Chang \\ Gung Memorial Hospital, Taoyuan, \\ Taiwan; ${ }^{5}$ Department of Public \\ Health, College of Medicine, Chang \\ Gung University, Taoyuan, Taiwan; \\ ${ }^{6}$ Biostatistics Core Laboratory, \\ Molecular Medicine Research \\ Center, Chang Gung University, \\ Taoyuan, Taiwan; ${ }^{7}$ Department of \\ Anesthesiology, Xiamen Changgung \\ Hospital, Xiamen, China
}

*These authors contributed equally to this work

Correspondence: Huang-Ping Yu Department of Anesthesiology, Chang Gung Memorial Hospital, 5 Fu-Shin Street, Kwei-Shan, Taoyuan 333, Taiwan

Tel $+8863328 \quad 1200$ ext 2324

Fax +886 $3328 I 200$ ext 2793

Email yuhp200I@adm.cgmh.org.tw
Background: Individuals with a family history of Parkinson's disease (PD) appear to have a higher risk of developing PD and other neuropsychiatric diseases. However, estimates of the relative risks (RRs) of PD and the roles of genetic and environmental factors in PD susceptibility are unclear. The aim of this study was to examine familial aggregation and genetic contributions to PD and the RRs of other neuropsychiatric diseases in relatives of PD patients.

Methods: In this population-based family cohort study, the records of all individuals actively registered in the Taiwan National Health Insurance Research Database in 2015 were queried $(\mathrm{N}=24,349,599)$. In total, 149,187 individuals with a PD-affected parent, 3,698 with an affected offspring, 3,495 with an affected sibling, and 15 with an affected twin were identified. Diagnoses of PD were ascertained between January 1, 1999, and December 31, 2015. The prevalence and RRs of PD and other neuropsychiatric diseases in individuals with first-degree relatives with PD, as well as the contributions of heritability and environmental factors to PD susceptibility were investigated.

Results: The prevalence of PD was $0.46 \%$ in the general population and $0.52 \%$ in individuals with first-degree relatives with PD. The RR (95\% CI) for PD was 2.20 (1.41-3.45) for siblings, 1.59 (1.47-1.73) for parents, $1.86(1.63-2.11)$ for offspring, 63.12 (16.45-242.16) for twins, and $1.46(1.41-1.52)$ for spouses. The RR $(95 \% \mathrm{CI})$ in individuals with first-degree relatives with PD was 1.66 (1.57-1.76) for essential tremor, 1.68 (1.61-1.75) for schizophrenia, and 1.20 (1.12-1.28) for Alzheimer's disease. The estimated contribution to the phenotypic variance of PD was $11.0 \%$ for heritability, $9.1 \%$ for shared environmental factors, and $79.9 \%$ for non-shared environmental factors.

Conclusion: First-degree relatives of PD patients are more likely to develop PD and other neuropsychiatric diseases. Environmental factors account for a high proportion of the phenotypic variance of PD.

Keywords: Parkinson's disease, familial risk, population-based family study

\section{Introduction}

Parkinson's disease (PD) is a common age-related neurodegenerative disorder that is characterized by the degeneration of dopaminergic neurons in the substantia nigra, leading to resting tremor, rigidity, bradykinesia, postural instability, and disability. ${ }^{1}$ The accompanying degeneration of other neurons in PD can cause non-motor manifestations, including autonomic symptoms such as constipation, psychiatric problems such as anxiety and depression, and cognitive decline. ${ }^{1}$ PD mainly affects elderly individuals and its incidence increases steadily with age; only around $5 \%-6 \%$ of PD cases have an onset age under 50 years (i.e., early-onset PD). ${ }^{2,3}$ As there are currently no 
available treatments that can cure or halt disease progression, the increasing prevalence of PD worldwide has imposed an overwhelming burden on aging societies. ${ }^{4}$

Although most PD cases are sporadic, the etiology of $\mathrm{PD}$ is generally ascribed to a combination of genetic and environmental factors. ${ }^{5,6}$ A large-scale genome-wide association study (GWAS) of European cohorts estimated that genetic factors explain at least one-fourth of the PD liability; however, known mutations explain only $6 \%-7 \%$ of the phenotypic variance. ${ }^{7}$ Additionally, a large GWAS of East Asian populations revealed novel Asian-specific loci and diverse associations with PD risk loci, suggesting that population differences contribute to the genetic heterogeneity in PD risk found between Europeans and East Asians. ${ }^{8,9}$ Environmental factors are considered to be another main cause of PD susceptibility, especially in late-onset PD. ${ }^{1}$ These putative risk factors for PD include pesticides, well water, organic solvents, and metal exposure, while inverse correlations exist for smoking and caffeine consumption. ${ }^{1}$

The familial aggregation of PD has been identified by case-control and twin cohort studies, with most studies reporting stronger familial aggregation for early-onset PD than in late-onset PD. ${ }^{10}$ A meta-analysis including 29 familial aggregation studies of $\mathrm{PD}$ estimated that the overall relative risk (RR) $(95 \% \mathrm{CI})$ for PD in affected first-degree relatives was $2.9(2.2-3.8)$ and that the RR $(95 \% \mathrm{CI})$ for early-onset PD was 4.7 (3.2-6.8), while the RR (95\% CI) for late-onset PD was 2.7 (1.9-3.9). ${ }^{11}$ Linkage analyses and whole exome sequencing of $\mathrm{PD}$-affected families have so far revealed $>20$ associated loci and 11 associated genes; these studies provide convincing evidence that polymorphic variants in these genes contribute to sporadic PD. ${ }^{12,13}$ The causative genes in the pathogenesis of PD might be involved in abnormal protein aggregation, mitochondrial or lysosomal dysfunction, the ubiquitin-proteasome system, and/or kinase signaling pathways. ${ }^{12}$ Even in the early stages of PD, neuropsychiatric abnormalities are frequently detected in patients with $\mathrm{PD}$. The coaggregation of PD with other neuropsychiatric diseases, such as essential tremor, depression, anxiety, and dementia, has been reported in the literature. ${ }^{14-16}$

Previous studies have identified the existence of causative genes and putative environmental factors in the familial aggregation of $\mathrm{PD}$, but the relative contributions of inheritance and environmental factors to PD susceptibility remain unclear. Besides, understanding the coaggregation of PD with other neuropsychiatric diseases is valuable information for individuals with a family history of PD. Therefore, we conducted this population-based cohort study using nationwide genealogy reconstructed from the National Health Insurance (NHI) database of Taiwan to estimate the extent of familial aggregation of PD by determining the RRs of PD in specific kinships and to assess the relative contributions of genetic, shared, and non-shared environmental factors to PD susceptibility. Moreover, we also estimated the RRs for other neuropsychiatric diseases in individuals with PD-affected first-degree relatives.

\section{Materials and methods}

We conducted a population-based family cohort study based on the NHI research database (NHIRD) of Taiwan. The NHI Program is a single-payer centralized disbursement system in Taiwan that was founded in 1995. By the end of 2015, the database covered over $99.6 \%$ of the residents of Taiwan. ${ }^{17}$ The NHI database records patients' demographic variables, insurance information (such as payroll, whom to cover, and start and end date of insurance), and original claims data, which contain the comprehensive medical information of the beneficiaries. All of the disease diagnosis data recorded during our study period (from 1999 to 2015) were coded using the International Classification of Diseases, Ninth Revision (ICD-9) codes. To protect the patients' privacy, all tractable personal information was de-identified before being released for research purposes.

The present study was approved by the Institutional Review Board of Chang Gung Medical Foundation, Taiwan (approval number: 201701505B0). As the data used in this study were completely anonymized, the requirement for informed consent was waived.

\section{Study population}

We included all individuals $(\mathrm{N}=24,349,599)$ with a valid insurance status in the NHI in 2015 as our source population. We searched the entire study population in the NHIRD to identify all individuals who had at least two outpatient visits to a neurologist or one hospital admission with a diagnostic code of PD (ICD-9 code: 332.0) in any calendar year between 1999 and 2015 in order to derive the PD cases for this study. In Taiwan, individuals suspected of having PD are usually referred to a neurologist for a definite diagnosis of PD, which adheres to the clinical diagnostic criteria for PD from the Movement Disorder Society. ${ }^{18}$ To improve diagnostic accuracy, patients with a diagnostic code of secondary parkinsonism, cerebrovascular disease, or head trauma at the time of diagnosis of PD were excluded. 


\section{Identification of first-degree relatives of PD patients}

The registry of beneficiaries, a subset of the NHIRD, contains information on the family relationships between the insured person and his or her blood relatives and spouse. A unique personal identification number for each beneficiary in Taiwan enables valid internal linkages among different subsets of the NHI database, and we were thereby able to establish family genealogy for this study. ${ }^{19}$ Parent-offspring and spousal relationships were identified directly from the NHIRD, while full siblings were identified as individuals with the same parents. Twins were identified as full siblings with the same date of birth ( \pm 1 day). However, twin zygosity could not be distinguished in the database. Finally, we grouped subjects into families after determining the family relationships of each individual within the family. ${ }^{19}$ We excluded twins from the sibling analysis and all half-siblings from the whole analysis.

\section{Ascertainment of other neuropsychiatric diseases}

We further estimated the extent of coaggregation with other neuropsychiatric diseases in the first-degree relatives of PD patients. Patients were identified as having a specific neuropsychiatric disease in the NHIRD if they had at least one hospital admission or two specialist outpatient visits using that specific ICD-9 diagnostic code, and patients were included in our analysis only if their diagnosis was made by a specialist. The neuropsychiatric diseases and accompanying ICD-9 codes analyzed in our study were as follows: schizophrenia (295), major depression (296.2, 296.3), anxiety (300.0), phobic disorder (300.2), Tourette syndrome (307.2), Alzheimer's disease (331), essential tremor (333.1), dystonia (333.8), spinocerebellar disease (334), amyotrophic lateral sclerosis (335.2), multiple sclerosis (340), and epilepsy (345).

\section{Statistical analysis}

The prevalence of PD was calculated between January 1, 1999, and December 31, 2015, for the general population and for individuals with PD-affected relatives. Individuals with valid insurance registration in 2015 who met the definition of PD were defined as PD for the determination of prevalence. We assessed the prevalence ratios between individuals with an affected relative and the general population as RRs. ${ }^{20}$

The Breslow-Cox proportional hazard model was used to estimate the prevalence risk ratios in this cross-sectional study by applying the same follow-up time to all subjects. ${ }^{21}$ In this study, the threshold liability model was used to estimate heritability and familial transmission. Heritability was defined as the relative contribution of genetic factors to phenotypic variance, and familial transmission was defined as the sum of the heritability and shared environmental proportions. The liability scale between siblings and spouses was compared under the assumption that spouses share the same environmental factors and siblings share both the same genetic and environmental factors for phenotypic variance. ${ }^{19}$ We restricted the family history within first-degree relatives and assumed a mean of two siblings per family. Moreover, we further estimated the coaggregation of PD with other neuropsychiatric diseases in the first-degree relatives of patients with PD using a marginal Cox proportional hazard model with the same follow-up time for all participants. The adjusted RRs of coaggregation with other neuropsychiatric diseases were estimated by using the adjusted prevalence ratios of a specific disease between affected first-degree relatives of PD patients and the general population. Covariates such as age, sex, occupation category, income level, place of residence, and family size were included to model the familial aggregation of PD and coaggregation with other neuropsychiatric diseases. All analyses were performed using SAS software, version 9.3 (SAS Institute Inc., Cary, NC, USA). Two-sided $p$ values $\leq 0.05$ were considered statistically significant.

\section{Results \\ PD prevalence in individuals with PD- affected relatives versus the general population}

In 2015, there were 112,037 patients with a diagnosis of PD out of the 24,349,599 individuals in the general population of Taiwan, which was equivalent to a crude prevalence of $0.46 \%$. The prevalence of PD in women $(0.48 \%)$ was slightly higher than the prevalence in men $(0.44 \%)$. A total of 156,048 individuals had at least one affected first-degree relative with PD: 149,187 had an affected parent, 3,698 had an affected offspring, 3,495 had an affected sibling, and 15 had an affected twin. Among the individuals with a PD-affected first-degree relative, the crude prevalence of PD was $0.52 \%$. The comparison between the demographic characteristics of the individuals with PD-affected first-degree relatives and those of the general population are shown in Table 1. Figure 1 shows that the age-specific prevalence of PD in individuals with PD-affected first-degree relatives was significantly higher than that in the general population of Taiwan. Analysis of the age-specific prevalence of PD showed that the crude prevalence of PD steeply accelerated after 65 years of age in both groups (Table 2). Figure 2 shows the onset age-specific prevalence of PD in individuals with affected first-degree 
Table I Demographics of individuals with PD-affected first-degree relatives compared with the general population of Taiwan

\begin{tabular}{|c|c|c|c|}
\hline Variables & First-degree relatives & General population & $p$-value \\
\hline Total participants, $\mathrm{n}$ & 156,048 & $24,349,599$ & \\
\hline Male sex, n (\%) & $96,799(62.03)$ & I2,087, I57 (49.64) & \\
\hline Age (mean $\pm S D$, years) & $47.74 \pm 13.44$ & $39.61 \pm 20.99$ & $<0.0001$ \\
\hline PD, n (\%) & $808(0.52)$ & I I2,037 (0.46) & $<0.0001$ \\
\hline Male & $498(0.51)$ & $52,85 \mathrm{I}(0.44)$ & \\
\hline Female & $310(0.52)$ & $59,186(0.48)$ & \\
\hline Place of residence, n (\%) & & & $<0.0001$ \\
\hline Urban & I07,537 (68.91) & $15,042,834(6 \mid .78)$ & \\
\hline Suburban & $4 I, 498(26.59)$ & $7,470,176(30.68)$ & \\
\hline Rural & $6,786(4.35)$ & $\mathrm{I}, 766,946(7.26)$ & \\
\hline Unknown & $227(0.15)$ & $69,643(0.29)$ & \\
\hline Income levels, n (\%) & & & $<0.0001$ \\
\hline Quintile I & $27,873(17.86)$ & $4,370,920(17.95)$ & \\
\hline Quintile 2 & 13,765 (8.82) & $3,343,883(13.73)$ & \\
\hline Quintile 3 & $34,359(22.02)$ & 6,86I,908 (28.18) & \\
\hline Quintile 4 & $31,434(20.14)$ & $4,650,927(19.1)$ & \\
\hline Quintile 5 & $48,600(31.14)$ & $5,117,925(21.02)$ & \\
\hline Unknown & $17(0.01)$ & $4,036(0.02)$ & \\
\hline Occupation, n (\%) & & & $<0.0001$ \\
\hline Dependents of the insured individuals & $22,683(14.54)$ & $8,277,273(33.99)$ & \\
\hline Civil servants, teachers, military personnel, and veterans & $|2,04|(7.72)$ & $914,425(3.76)$ & \\
\hline Non-manual workers and professionals & $63,279(40.55)$ & $7,575,578(31.11)$ & \\
\hline Manual workers & $36,423(23.34)$ & $4,892,634(20.09)$ & \\
\hline Other & $21,622(13.86)$ & $2,689,689(11.05)$ & \\
\hline
\end{tabular}

Abbreviation: PD, Parkinson's disease.

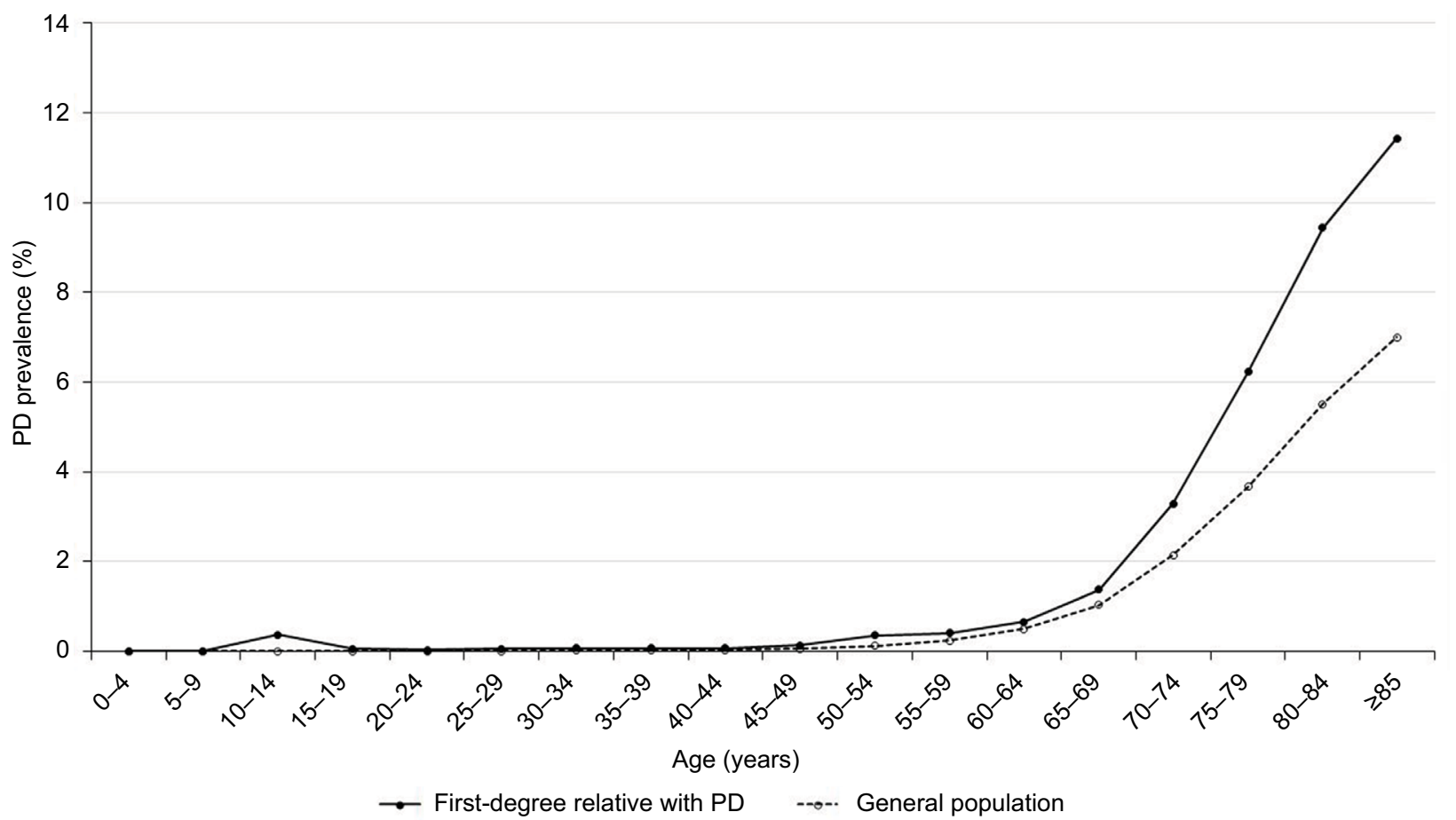

Figure I The age-specific prevalence of PD in individuals with affected first-degree relatives of PD and in the general population of Taiwan in 2015. Abbreviation: PD, Parkinson's disease. 
Table 2 Age-specific prevalence of PD in individuals with PD-affected first-degree relatives and in the general population of Taiwan in 2015

\begin{tabular}{|c|c|c|c|c|c|c|}
\hline \multirow[t]{2}{*}{ Age, years } & \multicolumn{3}{|c|}{ First-degree relatives with PD } & \multicolumn{3}{|c|}{ General population } \\
\hline & PD & $\begin{array}{l}\text { Total } \\
\text { population }\end{array}$ & Prevalence (\%) & PD & $\begin{array}{l}\text { Total } \\
\text { population }\end{array}$ & Prevalence (\%) \\
\hline $0-4$ & 0 & 192 & 0 & 5 & $\mathrm{I}, 05 \mathrm{I}, 252$ & 0.001 \\
\hline $5-9$ & 0 & 345 & 0 & 22 & 974,384 & 0.002 \\
\hline $10-14$ & 3 & 816 & 0.368 & 30 & $\mathrm{I}, \mathrm{I} 53,257$ & 0.003 \\
\hline $15-19$ & 1 & $\mathrm{I}, 850$ & 0.054 & 45 & $\mathrm{I}, 505,978$ & 0.003 \\
\hline $20-24$ & I & 3,436 & 0.029 & 109 & $1,748,135$ & 0.006 \\
\hline $25-29$ & 4 & 6,348 & 0.063 & 171 & $\mathrm{I}, 784,605$ & 0.010 \\
\hline $30-34$ & 9 & $|3,5| \mid$ & 0.067 & 313 & $2,094,877$ & 0.015 \\
\hline $35-39$ & 14 & 18,980 & 0.074 & 477 & $2,|57,5| 4$ & 0.022 \\
\hline $40-44$ & 10 & $|5,30|$ & 0.065 & 626 & $\mathrm{I}, 853,043$ & 0.034 \\
\hline $45-49$ & 28 & 19,972 & 0.14 & I,I 78 & $\mathrm{I}, 865,050$ & 0.063 \\
\hline $50-54$ & 87 & 24,231 & 0.359 & 2,286 & $\mathrm{I}, 876,470$ & 0.122 \\
\hline $55-59$ & 91 & 22,052 & 0.413 & 4,109 & $\mathrm{I}, 735,647$ & 0.237 \\
\hline $60-64$ & 104 & 15,827 & 0.657 & 7,625 & $\mathrm{I}, 519,30 \mathrm{I}$ & 0.502 \\
\hline $65-69$ & 102 & 7,390 & 1.38 & 10,089 & 980,756 & 1.029 \\
\hline $70-74$ & 89 & 2,709 & 3.285 & 14,666 & 683,830 & 2.145 \\
\hline $75-79$ & 89 & I,428 & 6.232 & 21,165 & 576,786 & 3.669 \\
\hline $80-84$ & 65 & 689 & 9.434 & 22,429 & 406,975 & 5.511 \\
\hline$\geq 85$ & 111 & 971 & 11.432 & 26,692 & 381,739 & 6.993 \\
\hline Total & 808 & 156,048 & 0.52 & 112,037 & $24,349,599$ & 0.46 \\
\hline
\end{tabular}

Abbreviation: PD, Parkinson's disease.

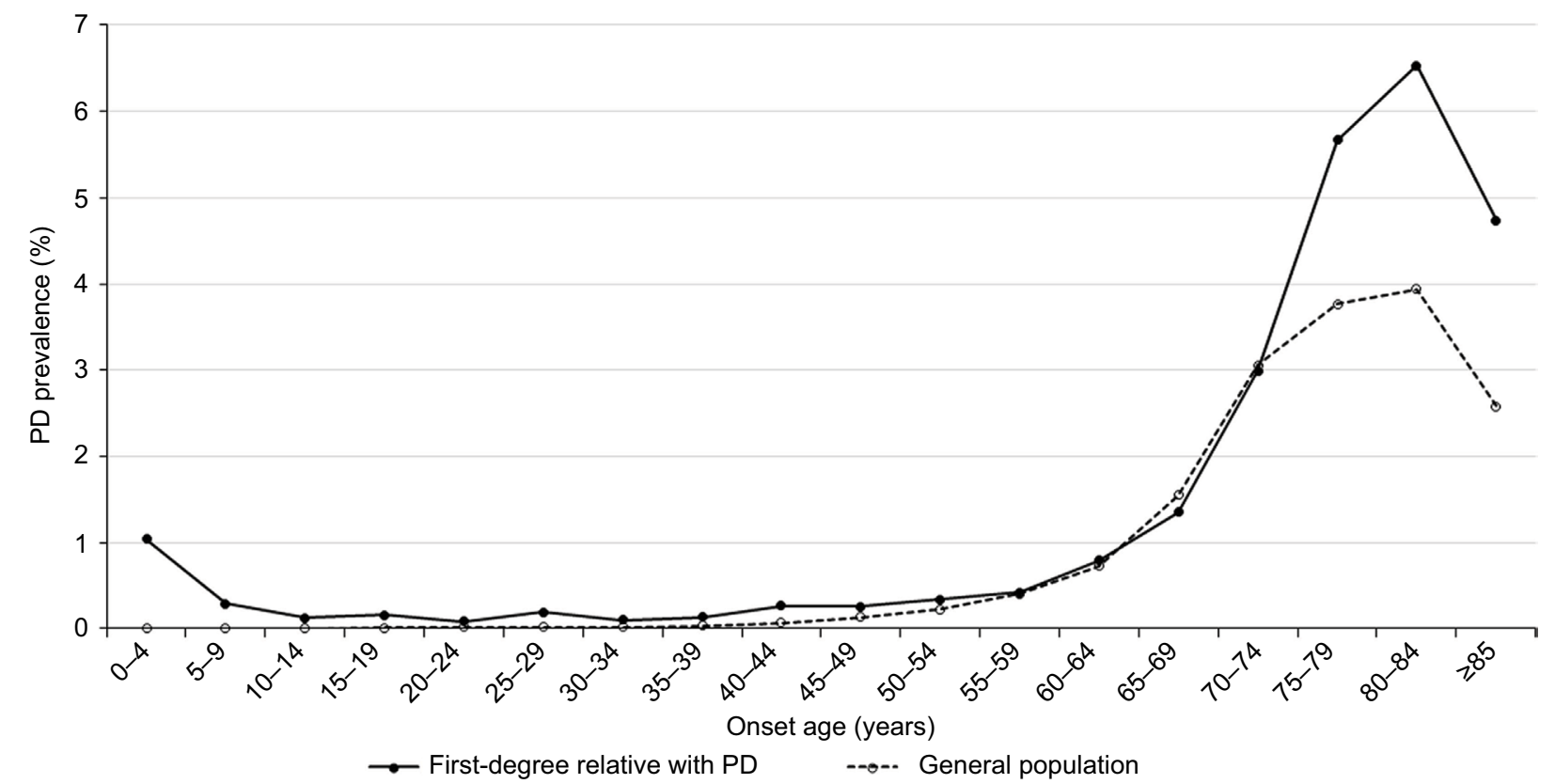

Figure 2 The onset age-specific prevalence of PD in individuals with affected first-degree relatives of PD and in the general population of Taiwan in 2015.

Abbreviation: PD, Parkinson's disease.

relatives of PD and that in the general population of Taiwan. The onset age-specific prevalence of PD in individuals with affected first-degree relatives of PD increased after the age of 60 years and then peaked at the age of 85 years.

\section{RRs for PD in individuals with PD-affected first-degree relatives}

The prevalence and adjusted RRs for PD in individuals with affected first-degree relatives of PD by the type of 
affected relative and sex are shown in Table 3. Overall, having a PD-affected first-degree relative was associated with an adjusted RR (95\% CI) for PD of 1.69 (1.56-1.83), and there was no significant difference between males (1.73 [1.56-1.92]) and females (1.68 [1.52-1.85]). The adjusted
RR (95\% CI) for PD among the first-degree relatives of PD patients was the most significant (63.12 [16.45-242.16]) for twins, that is, those with the highest genetic similarity, followed by $2.20(1.41-3.45)$ for siblings, $1.86(1.63-2.11)$ for offspring, 1.59 (1.47-1.73) for parents, and 1.46

Table 3 Relative risk of PD in individuals with PD-affected first-degree relatives compared with the general population of Taiwan

\begin{tabular}{|c|c|c|c|c|c|}
\hline $\begin{array}{l}\text { Type of affected } \\
\text { relative }\end{array}$ & $\begin{array}{l}\text { Sex of affected } \\
\text { relative }\end{array}$ & $\begin{array}{l}\text { Sex of } \\
\text { individual }\end{array}$ & $\begin{array}{l}\text { Number of } \\
\text { individuals with PD }\end{array}$ & Prevalence (\%) & $\begin{array}{l}\text { Adjusted relative } \\
\text { risks }^{\mathrm{a}}(95 \% \mathrm{Cls})\end{array}$ \\
\hline \multirow[t]{9}{*}{ Any } & Male & Male & 200 & $0.4 \mathrm{I}$ & $1.65(1.42-1.93)^{\mathrm{b}}$ \\
\hline & & Female & 182 & 0.56 & $1.82(1.58-2.09)^{\mathrm{b}}$ \\
\hline & & All & 382 & 0.47 & $1.73(1.56-1.92)^{\mathrm{b}}$ \\
\hline & Female & Male & 317 & 0.64 & $1.71(1.54-1.90)^{\mathrm{b}}$ \\
\hline & & Female & 132 & 0.47 & $1.63(1.32-2.00)^{\mathrm{b}}$ \\
\hline & & All & 449 & 0.58 & $1.68(1.52-1.85)^{\mathrm{b}}$ \\
\hline & All & Male & 498 & 0.51 & $1.66(1.52-1.82)^{\mathrm{b}}$ \\
\hline & & Female & 310 & 0.52 & $1.74(1.54-1.96)^{b}$ \\
\hline & & All & 808 & 0.52 & $1.69(1.56-1.83)^{\mathrm{b}}$ \\
\hline \multirow[t]{9}{*}{ Parent } & Male (father) & Male & 152 & 0.32 & $1.70(1.46-1.99)^{\mathrm{b}}$ \\
\hline & & Female & 51 & 0.17 & $1.50(1.14-1.97)^{\mathrm{b}}$ \\
\hline & & All & 203 & 0.26 & $1.65(1.44-1.89)^{\mathrm{b}}$ \\
\hline & Female (mother) & Male & 286 & 0.59 & $1.66(1.48-1.86)^{\mathrm{b}}$ \\
\hline & & Female & 88 & 0.33 & $\mathrm{I} .49(\mathrm{I} .2 \mathrm{I}-\mathrm{I} .83)^{\mathrm{b}}$ \\
\hline & & All & 374 & 0.5 & $1.60(1.45-1.77)^{\mathrm{b}}$ \\
\hline & All & Male & 419 & 0.45 & $\mathrm{I} .64(1.49-1.80)^{\mathrm{b}}$ \\
\hline & & Female & 135 & 0.24 & $1.48(1.25-1.75)^{\mathrm{b}}$ \\
\hline & & All & 554 & 0.37 & $1.59(1.47-1.73)^{\mathrm{b}}$ \\
\hline \multirow[t]{9}{*}{ Offspring } & Male (son) & Male & 34 & 3.82 & $1.33(0.96-1.84)$ \\
\hline & & Female & 122 & 7.24 & $1.98(1.67-2.34)^{\mathrm{b}}$ \\
\hline & & All & 156 & 6.06 & $1.79(1.54-2.08)^{\mathrm{b}}$ \\
\hline & Female (daughter) & Male & 22 & 5.19 & $2.26(1.52-3.36)^{\mathrm{b}}$ \\
\hline & & Female & 41 & 5.81 & $1.94(1.45-2.59)^{\mathrm{b}}$ \\
\hline & & All & 63 & 5.58 & $2.03(\mathrm{I} .6 \mathrm{I}-2.57)^{\mathrm{b}}$ \\
\hline & All & Male & 56 & 4.27 & $1.59(1.24-2.04)^{\mathrm{b}}$ \\
\hline & & Female & 163 & 6.83 & $\mathrm{I} .97(\mathrm{I} .7 \mathrm{I}-2.28)^{\mathrm{b}}$ \\
\hline & & All & 219 & 5.92 & $1.86(1.63-2.1 \mathrm{l})^{\mathrm{b}}$ \\
\hline \multirow[t]{9}{*}{ Sibling } & Male (brother) & Male & 12 & 0.89 & I.87 (0.88-3.96) \\
\hline & & Female & 9 & 0.88 & $2.00(1.04-3.87)^{\mathrm{b}}$ \\
\hline & & All & 21 & 0.89 & $1.92(1.15-3.20)^{\mathrm{b}}$ \\
\hline & Female (sister) & Male & 9 & 1.42 & $2.87(1.50-5.48)^{b}$ \\
\hline & & Female & 3 & 0.61 & $3.47(0.84-14.36)$ \\
\hline & & All & 12 & 1.07 & $2.97(1.62-5.45)^{b}$ \\
\hline & All & Male & 21 & 1.06 & $2.20(1.32-3.66)^{\mathrm{b}}$ \\
\hline & & Female & 12 & 0.79 & $2.23(1.2 \mathrm{I}-4.12)^{\mathrm{b}}$ \\
\hline & & All & 33 & 0.94 & $2.20(\mathrm{I} .4 \mathrm{I}-3.45)^{\mathrm{b}}$ \\
\hline \multirow[t]{9}{*}{ Twin } & Male (brother) & Male & 4 & 40 & $71.40(19.14-266.34)^{b}$ \\
\hline & & Female & $N / A$ & N/A & $\mathrm{N} / \mathrm{A}$ \\
\hline & & All & 4 & 36.36 & $66.63(17.24-257.48)^{\mathrm{b}}$ \\
\hline & Female (sister) & Male & $N / A$ & N/A & N/A \\
\hline & & Female & $N / A$ & N/A & $\mathrm{N} / \mathrm{A}$ \\
\hline & & All & $N / A$ & $N / A$ & $\mathrm{~N} / \mathrm{A}$ \\
\hline & All & Male & 4 & 40 & $71.40(19.14-266.34)^{b}$ \\
\hline & & Female & $N / A$ & $\mathrm{~N} / \mathrm{A}$ & $\mathrm{N} / \mathrm{A}$ \\
\hline & & All & 4 & 26.67 & $63.12(16.45-242.16)^{b}$ \\
\hline Spouse & All & & 3,225 & 4.7 & $1.46(1.4 \mathrm{I}-1.52)^{\mathrm{b}}$ \\
\hline
\end{tabular}

Notes: ${ }^{a}$ Adjusted for age, sex, place of residence, income levels, occupation, and family size. ${ }^{b} p<0.05$. N/A: no PD cases in affected twin. Abbreviations: N/A, not applicable; PD, Parkinson's disease. 
(1.41-1.52) for spouses without genetic similarity. Using a threshold liability model, we estimated that genetic factors (heritability), shared environmental factors, and non-shared environmental factors accounted for $11.0 \%, 9.1 \%$, and $79.9 \%$ of the phenotypic variance of PD in the Taiwanese population, respectively.

\section{Coaggregation of PD with other neuropsychiatric diseases}

The prevalence and adjusted RRs (95\% CIs) for other neuropsychiatric diseases in individuals with PD-affected first-degree relatives compared with the general population of Taiwan are presented in Table 4. Among all analyzed neuropsychiatric diseases, the adjusted RR $(95 \% \mathrm{CI})$ in individuals with PD-affected first-degree relatives was the highest for schizophrenia with an RR (95\% CI) of 1.68 (1.61-1.75), followed by $1.66(1.57-1.76)$ for essential tremor, 1.46 (1.23-1.73) for spinocerebellar disease, 1.42 (1.28-1.56) for phobic disorder, 1.35 (1.24-1.46) for dystonia, 1.29 (1.26-1.33) for major depression, 1.27 (1.24-1.30) for anxiety, 1.27 (1.03-1.56) for multiple sclerosis, $1.23(1.07-1.42)$ for Tourette syndrome, 1.22 (1.17-1.27) for epilepsy, 1.20 (1.12-1.28) for Alzheimer's disease, and 1.20 (0.94-1.54) for amyotrophic lateral sclerosis.

Table 4 Relative risk of other neuropsychiatric diseases in individuals with PD-affected first-degree relatives

\begin{tabular}{|c|c|c|c|c|c|c|}
\hline \multirow[t]{2}{*}{$\begin{array}{l}\text { Neuropsychiatric } \\
\text { diseases }\end{array}$} & \multirow[t]{2}{*}{ Sex } & \multicolumn{2}{|c|}{$\begin{array}{l}\text { With affected first-degree } \\
\text { relative }\end{array}$} & \multicolumn{2}{|c|}{ General population } & \multirow[t]{2}{*}{$\begin{array}{l}\text { Adjusted RR } \\
(95 \% \mathrm{Cl})\end{array}$} \\
\hline & & Number & Prevalence, \% & Number & Prevalence, \% & \\
\hline \multirow[t]{3}{*}{ Schizophrenia } & Male & $\mathrm{I}, 365$ & $\mathrm{I} .4 \mathrm{I}$ & 94,153 & 0.78 & $\mathrm{I} .70(\mathrm{I} .62-\mathrm{I} .79)^{\mathrm{b}}$ \\
\hline & Female & 783 & 1.32 & 88,381 & 0.72 & $1.69(1.57-1.81)^{\mathrm{b}}$ \\
\hline & All & 2,148 & 1.38 & 182,534 & 0.75 & $1.68(1.6 \mathrm{I}-\mathrm{I} .75)^{\mathrm{b}}$ \\
\hline \multirow[t]{3}{*}{ Essential tremor } & Male & 749 & 0.77 & 51,773 & 0.43 & I.82 (I.69-I.95) \\
\hline & Female & 438 & 0.74 & 63,342 & 0.52 & $\mathrm{I} .55(\mathrm{I} .4 \mathrm{I}-\mathrm{I} .70)^{\mathrm{b}}$ \\
\hline & All & $\mathrm{I}, 187$ & 0.76 & 115,115 & 0.47 & $\mathrm{I} .66(\mathrm{I} .57-\mathrm{I} .76)^{\mathrm{b}}$ \\
\hline \multirow[t]{3}{*}{ Phobic disorder } & Male & 241 & 0.25 & 17,727 & 0.15 & $\mathrm{I} .54(\mathrm{I} .36-\mathrm{I} .75)^{\mathrm{b}}$ \\
\hline & Female & 139 & 0.23 & 18,894 & 0.15 & $1.29(1.09-1.52)^{\mathrm{b}}$ \\
\hline & All & 380 & 0.24 & 36,621 & 0.15 & $1.42(1.28-1.56)^{b}$ \\
\hline \multirow[t]{3}{*}{ Spinocerebellar disease } & Male & 84 & 0.09 & 7,175 & 0.06 & $1.36(1.10-1.68)^{\mathrm{b}}$ \\
\hline & Female & 53 & 0.09 & 6,864 & 0.06 & $1.68(1.28-2.21)^{\mathrm{b}}$ \\
\hline & All & 137 & 0.09 & 14,039 & 0.06 & $1.46(1.23-1.73)^{\mathrm{b}}$ \\
\hline \multirow[t]{3}{*}{ Dystonia } & Male & 277 & 0.29 & 19,792 & 0.16 & $1.38(1.23-1.56)^{\mathrm{b}}$ \\
\hline & Female & 267 & 0.45 & 36,972 & 0.3 & $\mathrm{I} .35(\mathrm{I} .20-\mathrm{I} .52)^{\mathrm{b}}$ \\
\hline & All & 544 & 0.35 & 56,764 & 0.23 & $1.35(1.24-1.46)^{\mathrm{b}}$ \\
\hline \multirow[t]{3}{*}{ Multiple sclerosis } & Male & 33 & 0.03 & 2,534 & 0.02 & I.25 (0.89-I.76) \\
\hline & Female & 52 & 0.09 & 6,587 & 0.05 & $1.28(0.98-1.67)$ \\
\hline & All & 85 & 0.05 & $9,|2|$ & 0.04 & $1.27(1.03-1.56)^{\mathrm{b}}$ \\
\hline \multirow[t]{3}{*}{ Tourette syndrome } & Male & 144 & 0.15 & 41,788 & 0.35 & $1.39(1.18-1.63)^{\mathrm{b}}$ \\
\hline & Female & 50 & 0.08 & 15,739 & 0.13 & $1.20(0.91-1.58)$ \\
\hline & All & 194 & 0.12 & 57,527 & 0.24 & $\mathrm{I} .23(\mathrm{I} .07-\mathrm{I} .42)^{\mathrm{b}}$ \\
\hline \multirow[t]{3}{*}{ Epilepsy } & Male & $\mathrm{I}, 48 \mathrm{I}$ & 1.53 & 168,838 & $\mathrm{I} .4$ & $1.20(1.14-1.27)^{\mathrm{b}}$ \\
\hline & Female & 663 & 1.12 & 130,198 & 1.06 & $1.22(1.13-1.31)^{\mathrm{b}}$ \\
\hline & All & 2,144 & 1.37 & 299,036 & 1.23 & $1.22(1.17-1.27)^{\mathrm{b}}$ \\
\hline \multirow[t]{3}{*}{ Major depression } & Male & 2,236 & 2.31 & 162,863 & $\mathrm{I} .35$ & $1.37(1.32-1.43)^{\mathrm{b}}$ \\
\hline & Female & 2,181 & 3.68 & 292,342 & 2.38 & $1.26(1.21-1.31)^{\mathrm{b}}$ \\
\hline & All & 4,417 & 2.83 & 455,205 & $\mathrm{I} .87$ & $\mathrm{I} .29(\mathrm{I} .26-\mathrm{I} .33)^{\mathrm{b}}$ \\
\hline \multirow[t]{3}{*}{ Anxiety } & Male & 3,727 & 3.85 & 296,785 & 2.46 & $1.33(1.29-1.37)^{\mathrm{b}}$ \\
\hline & Female & 2,620 & 4.42 & 355,950 & 2.90 & $1.23(1.18-1.28)^{\mathrm{b}}$ \\
\hline & All & 6,347 & 4.07 & 652,735 & 2.68 & $\mathrm{I} .27(\mathrm{I} .24-\mathrm{I} .30)^{\mathrm{b}}$ \\
\hline \multirow[t]{3}{*}{ Alzheimer's disease } & Male & 550 & 0.57 & 73,580 & 0.61 & $1.18(1.08-1.28)^{b}$ \\
\hline & Female & 311 & 0.52 & 77,532 & 0.63 & $1.20(1.08-1.34)^{\mathrm{b}}$ \\
\hline & All & 861 & 0.55 & $15|| 12$, & 0.62 & $1.20(1.12-1.28)^{\mathrm{b}}$ \\
\hline Amyotrophic lateral & Male & 45 & 0.05 & 4,192 & 0.03 & I.I I (0.83-I.48) \\
\hline \multirow[t]{2}{*}{ sclerosis } & Female & 20 & 0.03 & 2,628 & 0.02 & $1.53(0.99-2.36)$ \\
\hline & All & 65 & 0.04 & 6,820 & 0.03 & I.20 (0.94-I.54) \\
\hline
\end{tabular}

Notes: aAdjusted for age, sex, place of residence, quintiles of income levels, occupation, and family size. ${ }^{b} p<0.05$. 


\section{Discussion}

This population-based family cohort study investigated the RRs of PD in individuals with PD-affected first-degree relatives and estimated the accountability of heritability and familial transmission for PD in the general population of Taiwan. The adjusted RR of PD in PD-affected first-degree relatives was 1.69 -fold higher than that in the general population, and the observed magnitude of RR was associated with genetic distance. The relative contributions of heritability and familial transmission to PD susceptibility in the Taiwanese population were estimated to be $11.0 \%$ and $20.1 \%$, respectively, which were relatively low compared to the $79.9 \%$ contribution of non-shared environmental factors. In addition, individuals with PD-affected first-degree relatives were at a higher risk of developing other neuropsychiatric diseases, particularly essential tremor, schizophrenia, spinocerebellar disease, and phobic disorder, than the general population.

Although most PD cases were sporadic, studies on the familial aggregation of PD have identified that autosomal recessive inheritance in early-onset $\mathrm{PD}$, variable genetic penetrance, and gene-environment interactions are all responsible for the heterogenetic presentation of PD. ${ }^{11}$ Inheritance also plays a substantial role in the susceptibility to sporadic PD, as demonstrated by a twin study which showed that subclinical dopaminergic dysfunction was concordant with $75 \%$ of clinical PD cases among monozygotic twins, but with only $22 \%$ of cases among dizygotic twins. ${ }^{22}$ Moreover, familial pedigree analyses have consistently shown higher RRs in siblings than in parents or offspring with the same genetic distance, suggesting that shared environmental exposure may increase PD susceptibility. ${ }^{11}$

Previous familial aggregation studies have reported much higher RRs for PD (range: 2.7-3.4) in the first-degree relatives of PD patients than we found in our study. ${ }^{23,24}$ However, those studies most often employed less robust sampling strategies, such as small numbers of familial pedigrees, hospital records, or telephone interviews, thus increasing selection bias and limiting generalizability. A recent population-based study using family history questionnaires found that the first-degree relatives of patients with PD had a higher risk of developing PD (RR: 1.988, $p=0.036$ ), which was more in line with our result. ${ }^{25}$ However, our estimate of heritability having only $11.0 \%$ of the accountability for PD in the Taiwanese population is relatively low compared with previous estimations made from genome-wide association analyses in European cohorts. ${ }^{7,26}$ This difference might be ascribed to differences in study populations and estimation methods.
Further GWAS focusing on the contribution of heritability to $\mathrm{PD}$ in other populations is warranted.

Genetic and environmental interactions play a crucial role in PD susceptibility. Environmental exposure can cause epigenetic modifications such as DNA methylation or histone modification, thus triggering or accelerating the development of PD in genetically susceptible individuals. ${ }^{27}$ An umbrella review that evaluated 75 meta-analyses on observational studies of risk factors for PD identified convincing evidences of causative associations with PD for head trauma, constipation, and depression, while protective roles were found for physical exercise and smoking. ${ }^{28}$ Other reported potential linkages between PD and environmental or behavioral exposures, including well water consumption, pesticide use, organic solvents, lead or manganese exposure, and higher education, have weaker evidence-based associations with PD. ${ }^{29-31}$ Further investigation on the genuine causative agents of PD and clarification of its underlying mechanisms is required.

Coaggregation of PD with other neuropsychiatric abnormalities has been reported in the literature. ${ }^{32}$ Genetic association studies have implied that PD might share common genetic mechanisms with other neuropsychiatric diseases; however, the variable magnitude of pathogenic overlap might contribute to diverse disease manifestations. ${ }^{32}$ Among all of the neuropsychiatric diseases analyzed in our study, individuals with PD-affected first-degree relatives had the highest risk of developing schizophrenia (RR: 1.68). Visual hallucination is the most common presentation of PD psychosis in PD patients, and it is also a prominent feature of schizophrenia. ${ }^{33}$ Furthermore, patients with schizophrenia exhibited the highest risk of developing subsequent PD among the patients with pre-existing psychiatric illnesses (hazard ratio: 8.9 ; 95\% CI: 7.74-10.24) ${ }^{34}$ Genetic risk profile studies have shown that schizophrenia shares spatially overlapping loci with PD and that their possible pathologic linkage might originate from dopaminergic system imbalance or dysfunction..$^{32}$ Essential tremor was also found to have a higher coaggregation with PD in our study (RR: 1.66). Both essential tremor and PD are characterized by pathologic tremor with progressively disabling entity, and they might also share the same Lewy body pathogenesis. ${ }^{16}$ Our coaggregation analysis found higher RRs for the development of spinocerebellar diseases (RR: 1.46) and dystonia (RR: 1.35) in the first-degree relatives of PD patients. Spinocerebellar degeneration, also known as spinocerebellar ataxia (SCA), can present as parkinsonism, particularly the SCA2, SCA3, and SCA17 subtypes. ${ }^{35}$ Patients who suffer from dystonic 
tremor and dopa-responsive dystonia might have PD-like resting tremor and cogwheel rigidity, but their results of dopamine transporter imaging are normal. ${ }^{36,37}$

Alzheimer's disease and PD are both age-related neurodegenerative diseases. They are thought to share the same cardinal mechanisms of neural damage, which are mainly characterized by the abnormal aggregation of misfolded proteins (amyloid $\beta$ in Alzheimer's disease and $\alpha$-synuclein in PD), oxidative stress, and mitochondrial dysfunction. ${ }^{38,39}$ A recent systematic review that included 16 familial coaggregation studies of PD and Alzheimer's disease concluded that there was only modest familial coaggregation of Alzheimer's disease in individuals with PD-affected relatives (RRs: 1.18-1.40), which is consistent with our result. ${ }^{40}$ Other psychiatric diseases, such as anxiety, depression, panic disorder, and phobia, are common non-motor presentations of PD, and their coaggregation with PD has been reported in previous studies, with RRs ranging from 1.45 to $1.87 .41-43$ The modest familial coaggregation with PD implies that these psychiatric diseases might share common familial susceptibility factors with PD. ${ }^{15}$

Our present study had several strengths and important implications. First, our population-based cohort study utilized the NHI database, which contains health information covering nearly the entire population of Taiwan, and its representativeness and clinical consistency are well documented. Second, we had stringent case ascertainment criteria for PD and other neuropsychiatric diseases in that required at least two outpatient visits to a specialist or one hospital admission diagnosis made by a specialist, which minimized selection and recall bias. Third, the reconstructed familial relationships could be ascertained for most permanent residents of Taiwan based on the solid linkage by unique personal identification numbers. Fourth, the threshold liability model is effective for estimating familial aggregation, and its applications have been previously validated. ${ }^{19}$ Altogether, our study provided objectively quantitative data that estimated the relative contributions of heritability and environmental factors for PD susceptibility, which is valuable information for the clinical consultation of individuals with a family history of PD.

However, there were several limitations to our study. First, disease identification was based on the ICD-9 diagnosis codes for each patient registered in the NHI database. Detailed information on clinical symptoms, laboratory testing, and examinations was unobtainable in the NHIRD. Second, this cross-sectional study analyzed the entire Taiwanese population registered in the NHI database in 2015 , so the incidence rate and onset age for each individual with PD were not evaluated.
Third, the zygosity of twins was not recorded in the NHI database, so a classic twin study design could not be utilized to estimate the relative contribution of heritability. Fourth, our threshold liability model was imperfect, as spouses may not share the same environmental factors as those shared by siblings. Finally, our study results are restricted to the population of Taiwan; therefore, it is not clear whether our results are applicable to other populations. Further studies are required to determine the generalizability of our results.

\section{Conclusion}

This population-based cohort study showed that individuals with PD-affected first-degree relatives had a 1.69-fold higher risk of developing PD and a higher risk of developing other neuropsychiatric diseases, such as schizophrenia, essential tremor, and phobic disorder. PD should be considered an age-related multifactorial syndrome with mainly genetic and environmental components. The estimated relative contributions to PD susceptibility in the Taiwanese population were $11.0 \%$ for heritability, $9.1 \%$ for shared environmental factors, and $79.9 \%$ for non-shared environmental factors. Our findings provide information useful for counseling families of PD patients. The environmental causative agents responsible for the majority of PD susceptibility and the contribution of heritability to PD phenotypic variance in other populations warrant further investigation.

\section{Acknowledgments}

This study was based in part on data from the NHIRD provided by the Bureau of National Health Insurance, Department of Health, and managed by the National Health Research Institutes. The interpretation and conclusions contained herein do not represent the views of the Bureau of National Health Insurance, Department of Health or the National Health Research Institutes. The work was funded by Chang Gung Memorial Hospital (CMRPG3E0132 and CMRPG3E0133) and the Maintenance Project for the Center of Big Data Analytics and Statistics (CLRPG3D0043) from Chang Gung Memorial Hospital.

\section{Disclosure}

The authors report no conflicts of interest in this work.

\section{References}

1. Wirdefeldt K, Adami HO, Cole P, Trichopoulos D, Mandel J. Epidemiology and etiology of Parkinson's disease: a review of the evidence. Eur J Epidemiol. 2011;26(Suppl 1):S1-S58.

2. Schrag A, Schott JM. Epidemiological, clinical, and genetic characteristics of early-onset Parkinsonism. Lancet Neurol. 2006;5(4):355-363. 
3. Wickremaratchi MM, Perera D, O’Loghlen C, et al. Prevalence and age of onset of Parkinson's disease in cardiff: a community based cross sectional study and meta-analysis. J Neurol Neurosurg Psychiatry. 2009;80(7):805-807.

4. Kowal SL, Dall TM, Chakrabarti R, Storm MV, Jain A. The current and projected economic burden of Parkinson's disease in the United States. Mov Disord. 2013;28(3):311-318.

5. Sveinbjörnsdottir S, Hicks AA, Jonsson T, et al. Familial aggregation of Parkinson's disease in Iceland. NEngl J Med. 2000;343(24):1765-1770.

6. Payami H, Zareparsi S, James D, Nutt J. Familial aggregation of Parkinson disease: a comparative study of early-onset and late-onset disease. Arch Neurol. 2002;59(5):848-850.

7. Do CB, Tung JY, Dorfman E, et al. Web-based genome-wide association study identifies two novel loci and a substantial genetic component for Parkinson's disease. PLoS Genet. 2011;7(6):e1002141.

8. Satake W, Nakabayashi Y, Mizuta I, et al. Genome-wide association study identifies common variants at four loci as genetic risk factors for Parkinson's disease. Nat Genet. 2009;41(12):1303-1307.

9. Foo JN, Tan LC, Irwan ID, et al. Genome-wide association study of Parkinson's disease in East Asians. Hum Mol Genet. 2017;26(1):226-232.

10. Tanner CM, Ottman R, Goldman SM, et al. Parkinson disease in twins: an etiologic study. JAMA. 1999;281(4):341-346.

11. Thacker EL, Ascherio A. Familial aggregation of Parkinson's disease: a meta-analysis. Mov Disord. 2008;23(8):1174-1183.

12. Corti $\mathrm{O}$, Lesage $\mathrm{S}$, Brice $\mathrm{A}$. What genetics tells us about the causes and mechanisms of Parkinson's disease. Physiol Rev. 2011;91(4):1161-1218.

13. Benitez BA, Davis AA, Jin SC, et al. Resequencing analysis of five Mendelian genes and the top genes from genome-wide association studies in Parkinson's disease. Mol Neurodegener. 2016;11:29.

14. Caballol N, Marti MJ, Tolosa E. Cognitive dysfunction and dementia in Parkinson disease. Mov Disord. 2007;22(Suppl 17):S358-S366.

15. Arabia G, Grossardt BR, Geda YE, et al. Increased risk of depressive and anxiety disorders in relatives of patients with Parkinson disease. Arch Gen Psychiatry. 2007;64(12):1385-1392.

16. Louis ED, Clark L, Ottman R. Familial aggregation and co-aggregation of essential tremor and Parkinson's disease. Neuroepidemiology. 2016;46(1):31-36.

17. National Health Insurance Administration, Ministry of Health and Welfare, Executive Yuan. 2015-2016 National Health Insurance Annual Report. December 2015. Available from: https://www.nhi. gov.tw/Resource/webdata/30285_1_National\%20Health\%20Insurance\%20in\%20Taiwan\%202015-2016\%20(bilingual).pdf. Accessed December 15, 2017.

18. Goetz CG, Tilley BC, Shaftman SR, et al; Movement Disorder Society UPDRS Revision Task Force. Movement Disorder Society-sponsored revision of the Unified Parkinson's Disease Rating Scale (MDSUPDRS): scale presentation and clinimetric testing results. Mov Disord. 2008;23(15):2129-2170.

19. Kuo CF, Grainge MJ, Valdes AM, et al. Familial aggregation of systemic lupus erythematosus and coaggregation of autoimmune diseases in affected families. JAMA Intern Med. 2015;175(9):1518-1526.

20. Risch N. Linkage strategies for genetically complex traits. I. Multilocus models. Am J Hum Genet. 1990;46(2):222-228.

21. Barros AJ, Hirakata VN. Alternatives for logistic regression in crosssectional studies: an empirical comparison of models that directly estimate the prevalence ratio. BMC Med Res Methodol. 2003;3:21.

22. Piccini P, Burn DJ, Ceravolo R, Maraganore D, Brooks DJ. The role of inheritance in sporadic Parkinson's disease: evidence from a longitudinal study of dopaminergic function in twins. Ann Neurol. 1999;45(5):577-582.
23. Marder K, Levy G, Louis ED, et al. Familial aggregation of early- and late-onset Parkinson's disease. Ann Neurol. 2003;54(4):507-513.

24. Shino MY, McGuire V, Van Den Eeden SK, et al. Familial aggregation of Parkinson's disease in a multiethnic community-based case-control study. Mov Disord. 2010;25(15):2587-2594.

25. Gaare JJ, Skeie GO, Tzoulis C, Larsen JP, Tysnes OB. Familial aggregation of Parkinson's disease may affect progression of motor symptoms and dementia. Mov Disord. 2017;32(2):241-245.

26. Keller MF, Saad M, Bras J, et al; International Parkinson's Disease Genomics Consortium (IPDGC); Wellcome Trust Case Control Consortium 2 (WTCCC2). Using genome-wide complex trait analysis to quantify 'missing heritability' in Parkinson's disease. Hum Mol Genet. 2012;21(22):4996-5009.

27. Trinh J, Guella I, Farrer MJ. Disease penetrance of late-onset parkinsonism: a meta-analysis. JAMA Neurol. 2014;71(12):1535-1539.

28. Bellou V, Belbasis L, Tzoulaki I, Evangelou E, Ioannidis JP. Environmental risk factors and Parkinson's disease: an umbrella review of meta-analyses. Parkinsonism Relat Disord. 2016;23:1-9.

29. Breckenridge CB, Berry C, Chang ET, Sielken RL Jr, Mandel JS. Association between Parkinson's disease and cigarette smoking, rural living, well-water consumption, farming and pesticide use: systematic review and meta-analysis. PLoS One. 2016;11(4):e0151841.

30. Goldman SM, Quinlan PJ, Ross GW, et al. Solvent exposures and Parkinson disease risk in twins. Ann Neurol. 2012;71(6):776-784.

31. Valdes EG, Andel R, Sieurin J, et al. Occupational complexity and risk of Parkinson's disease. PLoS One. 2014;9(9):e106676.

32. Nalls MA, Saad M, Noyce AJ, et al. Genetic comorbidities in Parkinson's disease. Hum Mol Genet. 2014;23(3):831-841.

33. Gibson G, Mottram PG, Burn DJ, et al. Frequency, prevalence, incidence and risk factors associated with visual hallucinations in a sample of patients with Parkinson's disease: a longitudinal 4-year study. Int $J$ Geriatr Psychiatry. 2013;28(6):626-631.

34. Lin HL, Lin HC, Chen YH. Psychiatric diseases predated the occurrence of Parkinson disease: a retrospective cohort study. Ann Epidemiol. 2014;24(3):206-213.

35. van Gaalen J, Giunti P, van de Warrenburg BP. Movement disorders in spinocerebellar ataxias. Mov Disord. 2011;26(5):792-800.

36. Brooks DJ. Molecular imaging of dopamine transporters. Ageing Res Rev. 2016;30:114-121.

37. Cilia R, Reale C, Castagna A, et al. Novel DYT11 gene mutation in patients without dopaminergic deficit (SWEDD) screened for dystonia. Neurology. 2014;83(13):1155-1162.

38. Jiang T, Sun Q, Chen S. Oxidative stress: a major pathogenesis and potential therapeutic target of antioxidative agents in Parkinson's disease and Alzheimer's disease. Prog Neurobiol. 2016;147:1-19.

39. Ganguly G, Chakrabarti S, Chatterjee U, Saso L. Proteinopathy, oxidative stress and mitochondrial dysfunction: cross talk in Alzheimer's disease and Parkinson's disease. Drug Des Devel Ther. 2017;11:797-810.

40. Feldman AL, Johansson AL, Lambert PC, et al. Familial coaggregation of Alzheimer's disease and Parkinson's disease: systematic review and meta-analysis. Neuroepidemiology. 2014;42(2):69-80.

41. Pontone GM, Palanci J, Bienvenu OJ, et al. Familial aggregation of panic disturbances in Parkinson's disease. J Neuropsychiatry Clin Neurosci. 2011;23(4):417-424.

42. Gustafsson H, Nordström A, Nordström P. Depression and subsequent risk of Parkinson disease: a nationwide cohort study. Neurology. 2015;84(24):2422-2429.

43. Broen MP, Narayen NE, Kuijf ML, Dissanayaka NN, Leentjens AF. Prevalence of anxiety in Parkinson's disease: a systematic review and meta-analysis. Mov Disord. 2016;31(8):1125-1133. 
Clinical Epidemiology is an international, peer-reviewed, open access, online journal focusing on disease and drug epidemiology, identification of risk factors and screening procedures to develop optimal preventative initiatives and programs. Specific topics include: diagnosis, prognosis, treatment, screening, prevention, risk factor modification,

Submit your manuscript here: https://www.dovepress.com/clinical-epidemiology-journal
Dovepress

systematic reviews, risk and safety of medical interventions, epidemiology and biostatistical methods, and evaluation of guidelines, translational medicine, health policies and economic evaluations. The manuscript management system is completely online and includes a very quick and fair peer-review system, which is all easy to use. 